University of Louisville

ThinkIR: The University of Louisville's Institutional Repository

Faculty Scholarship

$5-21-2015$

Corrigendum: Responses to catastrophic AGI risk: A survey (2015

Phys. Scr. 90 018001)

Kaj Sotala

Machine Intelligence Research Institute

Roman V. Yampolskiy

University of Louisville, roman.yampolskiy@louisville.edu

Follow this and additional works at: https://ir.library.louisville.edu/faculty

Part of the Computer Engineering Commons

Original Publication Information

Kaj Sotala and Roman V Yampolskiy 2015 Phys. Scr. 90069501

DownloadArticle PDF

ThinkIR Citation

Sotala, Kaj and Yampolskiy, Roman V., "Corrigendum: Responses to catastrophic AGI risk: A survey (2015 Phys. Scr. 90 018001)" (2015). Faculty Scholarship. 589.

https://ir.library.louisville.edu/faculty/589

This Article is brought to you for free and open access by ThinkIR: The University of Louisville's Institutional Repository. It has been accepted for inclusion in Faculty Scholarship by an authorized administrator of ThinkIR: The University of Louisville's Institutional Repository. For more information, please contact thinkir@louisville.edu. 
CORRIGENDUM

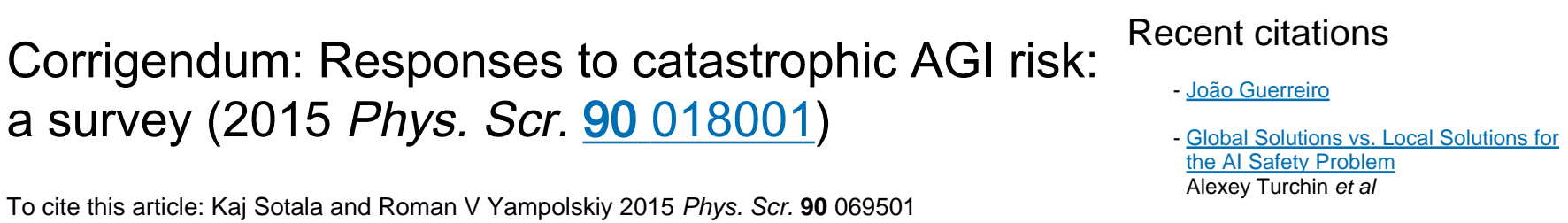

View the article online for updates and enhancements. 


\title{
Corrigendum: Responses to catastrophic AGI risk: a survey (2015 Phys. Scr. 90 018001)
}

\author{
Kaj Sotala ${ }^{1}$ and Roman V Yampolskiy ${ }^{2}$ \\ ${ }^{1}$ Machine Intelligence Research Institute, Berkeley, CA, USA \\ ${ }^{2}$ University of Louisville, KY, USA
}

Parts of the reference list are corrected to the following:

[105] Goertzel B 2002 Thoughts on AI morality Dynamical Psychology (ww.goertzel.org/dynapsyc/2002/ AIMorality.htm)

[106] Goertzel B 2004 Encouraging a positive transcension Dynamical Psychology (www.goertzel.org/dynapsyc/2004/ PositiveTranscension.htm)

[107] Goertzel B 2004 Growth, choice and joy Dynamical Psychology (www.goertzel.org/dynapsyc/2004/ GrowthChoiceJoy.htm)

[108] Goertzel B 2006 Apparent limitations on the 'AI friendliness' and related concepts imposed by the complexity of the world (www.goertzel.org/papers/LimitationsOnFriendliness.pdf)

[109] Goertzel B 2010 Coherent aggregated volition The Multiverse According to Ben (http:// multiverseaccordingtoben.blogspot.ca/2010/03/coherentaggregated-volition-toward.html)

[110] Goertzel B 2010 GOLEM (http://goertzel.org/GOLEM.pdf)

[111] Goertzel B 2012 Should humanity build a global AI nanny to delay the singularity until it's better understood? J. Consciousness Stud. 19 96-111

[112] Goertzel B 2012 When should two minds be considered versions of one another? Int. J. Mach. Consciousness 4 $177-85$

[113] Goertzel B 2012 CogPrime (http://wiki.opencog.org/w/ CogPrime_Overview)

[114] Goertzel B and Bugaj S V 2008 Stages of ethical development in artificial general intelligence systems Artificial General Intelligence (Frontiers in Artificial Intelligence and Applications no. 171) (Amsterdam: IOS) pp 448-59

[115] Goertzel B and Pitt J 2012 Nine ways to bias open-source AGI toward friendliness J. Evol. Technol. 22 116-31

[133] Hanson R 1994 If uploads come first Extropy 6 10-15

[134] Hanson R 1998 Economic growth given machine intelligence (http://hanson.gmu.edu/aigrow.pdf)

[135] Hanson R 2007 Shall we vote on values, but bet on beliefs? (http://hanson.gmu.edu/futarchy.pdf)

[136] Hanson R 2008 Economics of the singularity IEEE Spectr. 45 $45-50$

[137] Hanson R 2009 Prefer law to values Overcoming Bias (www. overcomingbias.com/2009/10/prefer-law-to-values.html)
[138] Hanson R 2012 Meet the new conflict, same as the old conflict J. Consciousness Stud. 19 119-25

[146] Hibbard B 2001 Super-intelligent machines ACM SIGGRAPH Comput. Graph. 35 13-5

[147] Hibbard B 2005 The ethics and politics of super-intelligent machines (https://sites.google.com/site/whibbard/g/ SI_ethics_politics.doc)

[148] Hibbard B 2005 Critique of the SIAI collective volition theory (www.ssec.wisc.edu/ billh/g/ SIAI_CV_critique.html)

[149] Hibbard B 2008 Open source AI Artificial General Intelligence Frontiers (Artificial Intelligence and Applications no. 171) ed P Wang, B Goertzel and S Franklin (Amsterdam: IOS) pp 473-7

[150] Hibbard B 2012 Model-based utility functions J. Artificial Gen. Intell. 3 1-24

[151] Hibbard B 2012 Decision support for safe AI design Artificial General Intelligence (Lecture Notes in Artificial Intelligence no. 7716) ed J Bach, B Goertzel and M Ikl (New York: Springer) pp 117-25

[152] Hibbard B 2012 The error in my 2001 VisFiles column (www.ssec.wisc.edu/ billh/g/visfiles_error.html)

[153] Hibbard B 2012 Avoiding unintended AI behaviors Artificial General Intelligence (Lecture Notes in Artificial Intelligence no. 7716) ed J Bach, B Goertzel and M Ikl (New York: Springer) pp 107-16

[306] Yudkowsky E 1996 Staring into the singularity (http:// yudkowsky.net/obsolete/singularity.html)

[307] Yudkowsky E 2001 Creating friendly AI 1.0 (http:// intelligence.org/files/CFAI.pdf)

[308] Yudkowsky E 2004 Coherent extrapolated volition (http:// intelligence.org/files/CEV.pdf)

[309] Yudkowsky E 2011 Artificial intelligence as a positive and negative factor in global risk Global Catastrophic Risks ed N Bostrom and M M Cirkovic (Oxford: Oxford University Press) pp 308-45

[310] Yudkowsky E 2008 Hard takeoff Less Wrong (http:// lesswrong.com/lw/wf/hard takeoff/)

[311] Yudkowsky E 2009 Value is fragile Less Wrong (http:// lesswrong.com/lw/y3/value_is_fragile/)

[312] Yudkowsky E 2011 Complex value systems are required to realize valuable futures (http://intelligence.org/files/ ComplexValues.pdf)

[313] Yudkowsky E 2012 Reply to Holden on tool AI Less Wrong (http://lesswrong.com/lw/cze/reply_to_holden_on_tool_ai/) 